\title{
RELIEF registry: large-scale evidence on the safety and long-term efficacy of focused ultrasound treatment of symptomatic leiomyoma
}

\author{
Arik Hananel ${ }^{1 *}$, Elizabeth David ${ }^{2}$, Wladyslaw Gedroyc ${ }^{3}$, Young-sun $\mathrm{Kim}^{4}{ }^{4}$, Matthias Matzko ${ }^{5}$, Harsh Rastogi ${ }^{6}$, \\ Anne Roberts ${ }^{7}$, Elizabeth Stewart ${ }^{8}$, Robert Zurawin ${ }^{9}$, Jaron Rabinovici ${ }^{10}$ \\ From Current and Future Applications of Focused Ultrasound 2014. 4th International Symposium \\ Washington, D.C, USA. 12-16 October 2014
}

\section{Background/introduction}

In this work we will present our plan for an (MR)-guided, high-intensity focused ultrasound (FUS) uterine fibroid registry, with the goal of providing large-scale evidence on the safety and long-term efficacy of FUS for the treatment of symptomatic uterine fibroids.

\section{Methods}

1,000 patients will be enrolled to the registry in multiple sites worldwide. Patient would get FUS treatment and be followed for a period of three years. Only FUS qualified patients and sites meeting registry treatment criteria would participate in the study.

\section{Results and conclusions}

Treatment outcome and follow-up data will be collected by a contract research organization, (CRO), and analyzed for safety and efficacy. We will then compare our results to similar results in the literature. Subgroups will be selected and analyzed to address heterogeneity and usage of non-uniform treatment methods.

\begin{abstract}
Authors' details
${ }^{1}$ Focused Ultrasound Foundation, Charlottesville, Virginia, United States. ${ }^{2}$ Sunnybrook Health Sciences Centre, Toronto, Canada. ${ }^{3}$ Imperial College London, London, United Kingdom. ${ }^{4}$ Samsung Medical Center, Seoul, Republic of Korea. ${ }^{5}$ Amper Kliniken AG, Dachau, Germany. ${ }^{6}$ Indraprastha Apollo Hospital, Delhi, India. ${ }^{7}$ University of California at San Diego, San Diego, California, United States. ${ }^{8}$ Mayo Clinic, Rochester, Minnesota, United States. ${ }^{9}$ Baylor College of Medicine, Houston, Texas, United States. ${ }^{10}$ Sheba Medical Center, Tel Hashomer, Israel.
\end{abstract}

Published: 30 June 2015

Focused Ultrasound Foundation, Charlottesville, Virginia, United States Full list of author information is available at the end of the article
doi:10.1186/2050-5736-3-S1-094

Cite this article as: Hananel et al:: RELIEF registry: large-scale evidence on the safety and long-term efficacy of focused ultrasound treatment of symptomatic leiomyoma. Journal of Therapeutic Ultrasound 2015 3(Suppl 1):094.
Submit your next manuscript to BioMed Central and take full advantage of:

- Convenient online submission

- Thorough peer review

- No space constraints or color figure charges

- Immediate publication on acceptance

- Inclusion in PubMed, CAS, Scopus and Google Scholar

- Research which is freely available for redistribution

Submit your manuscript at www.biomedcentral.com/submit 